\title{
The Impact of Agency on Time and Risk Preferences
}

\author{
Ayelet Gneezy ${ }^{\mathrm{a}}$, Alex Imas ${ }^{\mathrm{b}, *}, \&$ Ania Jaroszewicz ${ }^{\mathrm{b}}$
}

September 2018

\begin{abstract}
Scholars have long argued for the central role of agency in the human experience. In this paper, we demonstrate the importance of agency in shaping people's patience and risk tolerance. We focus on the context of resource scarcity, which has been associated with both impatience and a lack of agency. Using data from a representative sample of over 86,000 individuals worldwide and two experiments, we replicate the decrease in patience among those exposed to scarcity. However, we show that endowing individuals with agency over scarcity fully moderates this effect, increasing patience substantially. We further show that agency's impact on patience is partly driven by greater risk tolerance. These results hold even though individuals with greater agency do not exercise it; simply knowing one could alleviate one's scarcity is sufficient to change behavior. Finally, we demonstrate that these effects of agency generalize beyond scarcity, highlighting the potential for agency-based policy and institutional design.
\end{abstract}

a. UC San Diego, Rady School of Management

b. Carnegie Mellon University, Social \& Decision Sciences

* Corresponding author: 5000 Forbes Ave., PH 208, Pittsburgh, PA 15213 aimas@andrew.cmu.edu 
The importance of personal agency has been discussed as early as Aristotle's

Nicomachean Ethics. Prominent philosophers (Rawls, 1971), political scientists (Berlin, 1969), and economists across the ideological spectrum—-from Marx (Marx \& Engels, 1947) to Friedman (Friedman \& Friedman, 1990) — have all argued for the central role of agency in the human experience. Typically defined in relation to an individual's choice set, where a larger set of opportunities is associated with greater agency (Sen, 1988), the value of personal agency has been attributed to two main sources. Economists have primarily focused on the purely instrumental value of agency: a larger choice set increases the potential to select an option that leads to greater utility (Friedman \& Friedman, 1990). Philosophers and psychologists have argued for the intrinsic value of personal agency, positing that people may value greater agency as an end in itself (Brehm, 1966; Carter, 1995; Landau, Kay, \& Whitson, 2015; Langer, 1983). Indeed, individuals whose agency has been diminished seek to punish those deemed responsible (Falk \& Kosfeld, 2006), are willing to pay significant amounts of money to restore it (Gneezy, Imas, \& Ariely, 2016), and score higher on measures of well-being when it is restored (Langer \& Rodin, 1976; Schulz, 1976) — even when the increased agency carries no pecuniary benefits.

The current paper focuses on the important role of personal agency along a third dimension: shaping people's preferences. Specifically, we examine how agency over one's environment affects one's level of patience and tolerance for risk. Our results show that increasing personal agency leads to greater willingness to wait for larger, later rewards over smaller, sooner rewards, and increases risk tolerance. Importantly, we show these effects hold even though individuals do not exercise the greater agency, suggesting that the mere perception that one has agency is sufficient to produce these effects. Our results carry significant 
implications for the role of personal agency in decisions involving tradeoffs over time and risk, such as whether to save for the future, go to school, or adopt and maintain a healthier lifestyle.

Why would agency affect patience and tolerance for risk? Prior work has shown that compared to people with a relatively low sense of agency, people with a greater sense of agency perceive prospects as less risky, believing that negative outcomes are less likely to occur (Crisp \& Barber, 1995; Nordgren, Van Der Pligt, Van Harreveld, 2007). These findings imply that people with a greater sense of agency should be more willing to take on risk, compared to those with less agency (Langer, 1975). Such changes in preferences have implications for intertemporal choice (Dasgupta \& Maskin, 2005). Decisions over time inherently involve a tradeoff between different levels of risk: the more distant future is less certain than dates closer to the present (Epper, Fehr-Duda, Bruhin, 2011). Researchers (Halevy, 2008) have argued that this difference in uncertainty can at least partially explain myopia and impatience: if delayed rewards are more uncertain than sooner rewards, then people who are more averse to risk should prefer smaller, sooner rewards to larger, later ones because the former are associated with less uncertainty. Consequently, if agency indeed increases risk tolerance, those with greater agency should be more patient and prefer larger, later rewards.

To motivate our investigation of the relationship between personal agency and decisionmaking, we first use the 2010-2014 World Values Survey multinational dataset (Inglehart, et al., $2014 ; N=86,272 ; 61$ countries). We aim to test whether higher levels of reported agency are associated with higher reported savings, which can be interpreted as a manifestation of greater patience (Lynch \& Zauberman, 2006; Laibson, 1997). In this survey, participants are asked whether, in the last year, their family had saved money, just gotten by, spent some savings, or spent savings and borrowed money. We use these responses to capture reported savings. To 
capture agency, we use responses to the question, "Some people feel they have completely free choice and control over their lives, while other people feel that what they do has no real effect on what happens to them. Please use this scale where 1 means 'none at all' and 10 means 'a great deal' to indicate how much freedom of choice and control you feel you have over the way your life turns out."

Our analyses show that even when controlling for a host of explanatory variables such as levels of income, employment, marital status, and education, people's reported levels of agency explain a significant proportion of their savings behavior: people who report a greater sense of agency save significantly more (Ordinary Least Squares [OLS] regression with robust standard errors [SEs], clustering at the country level, $p=.001$ ). This relationship is robust to different model specifications (see Supplemental Table 1 in Appendix D) and holds for both Organisation for Economic Cooperation and Development (OECD) and non-OECD countries (see Supplemental Table 2). Additionally, we can test whether personal agency can explain variation in reported savings that cannot be captured by standard economic determinants considered in the literature. We first regress savings on employment, income, and a multitude of other explanatory variables, using robust standard errors and clustering at the country level. We then regress the residuals from this model on agency. Supplemental Figure 1 in Appendix C illustrates the significant positive relationship between the unexplained variation in savings and individuals' reported agency $(p<.0005)$, showing the relationship both dividing by country and collapsing across countries.

This paper reports results from two experiments that provide empirical support for the proposed causal effect of agency on behavior. In both studies, participants were placed in an aversive environment and endowed with different levels of agency over it: some had the 
opportunity to alleviate their state, whereas others did not. In the first study, participants faced resource scarcity: they were asked to work on a task but did not have enough time to complete it. Participants who had the option to alleviate the scarcity - to increase the time allotted to the task - were substantially more patient on a subsequent task than those who lacked it: they were significantly more likely to prefer a larger, later financial reward to a smaller, sooner one. These results hold despite the fact that these participants did not exercise their agency (i.e., they did not choose to alleviate the scarcity), suggesting that merely knowing that one has the option to improve one's circumstances is sufficient to promote greater patience. In fact, the choices made by participants who had agency were indistinguishable from those made by participants who did not face scarcity at all. Further, our analyses reveal that the relationship between agency and patience is mediated by changes in risk tolerance: a lack of agency decreases willingness to take on risk, which, in turn, decreases patience.

Our second study tested whether the effect of agency on behavior can be generalized to other settings - specifically, exposure to environmental stressors. Participants were asked to complete a task while being exposed to aversive noise. Some had agency over this state — an option to alleviate the noise - whereas others did not. As in the first study, we find that people who had greater agency were subsequently more likely to wait for a larger, later reward than to select a smaller, sooner one. Again, this increase in patience occurred despite the fact that people who had the option to alleviate the noise did not exercise it, meaning both groups were exposed to the same level of environmental stressor.

Our findings contribute to the literature on the effects of adverse states such as scarcity on preferences and behavior. Resource scarcity has been linked with greater risk aversion (Dohmen, et al., 2011), greater discounting of the future (Carvalho, 2010; Lawrance, 1991), and 
a greater propensity to engage in behaviors involving immediate rewards and delayed costs, such as smoking (WHO, 2004). Researchers have proposed that this shift in behavior is driven by the experience of scarcity itself (Haushofer \& Fehr, 2014; Mullainathan \& Shafir, 2013).

Experiencing scarcity has been shown to drive greater risk aversion (Guiso \& Paiella, 2008) and lead to less patient decisions (Haushofer, Schunk, \& Fehr, 2013; Shah, Mullainathan, \& Shafir, 2012). In these studies, however, people who experienced scarcity also often lacked agency over that condition: they had no option to alleviate that state. Thus, it is difficult to identify the extent to which the state of scarcity per se-rather than the lack of agency over the state-contributed to the observed effects. Our findings suggest that agency may, in fact, play a key role in the previously documented relationship between scarcity and impatience: increasing perceived agency among those facing scarcity seems to mitigate the behavioral effects of experiencing the state.

The results presented in this paper are particularly pertinent in light of recent findings documenting the success of poverty-alleviation programs offering unconditional cash transfers to people living in poverty (e.g., GiveDirectly). These programs have been shown, for instance, to significantly improve outcomes such as schooling and physical health (Aizer, Eli, Ferrie, \& Lleras-Muney, 2016). Rather than limiting individuals' options like the more traditional in-kind benefit transfers, unconditional cash transfers allow recipients to choose exactly how to spend their money, thereby increasing their personal agency. Our findings suggest that this increase in agency may not only have instrumental and/or intrinsic benefits, it may also lead the recipients to use the funds less myopically.

\section{Study 1}


Our first study tested whether agency over resource scarcity affects people's patience and tolerance for risk. Participants were recruited from Amazon Mechanical Turk $(N=220)$ and randomly assigned to one of three conditions that manipulated the level of scarcity and agency: Scarcity-Agency (hereafter Agency), Scarcity-No Agency (hereafter No Agency), and a condition with no scarcity (hereafter Control).

\section{Methods}

This experiment was approved by the Carnegie Mellon University IRB. It complied with all relevant ethical regulations and involved informed consent. In the first part of the study, all participants responded to a set of 15 true-false cognitive aptitude questions adapted from the Wonderlic Cognitive Ability Test (e.g., "A farmer had 17 sheep. All but 9 died. There are 36 feet on the remaining sheep.")

Building on prior work (Shah, Mullainathan, \& Shafir, 2012), we manipulated resource scarcity by varying the amount of time participants had to answer the questions. Participants in both scarcity groups faced time scarcity: they had 10 seconds to answer each question, at the end of which the screen automatically advanced to the next question. Participants in the Control condition $(N=75)$ did not face scarcity — they had unlimited time to answer the questions. All participants were paid a base payment and a bonus for each correct answer. See Appendix A for detailed measures and instructions.

Next, participants answered a second set of 15 true-false cognitive aptitude questions under a different incentive structure. Participants were informed that once they were done, a number between 1 and 15 would be randomly drawn to serve as a threshold. Participants' whose number of correct answers met or exceeded this threshold would receive a bonus, which would double their payment; otherwise, they would receive no bonus. For this second task, participants 
in the Scarcity conditions experienced increased scarcity: they now had only six (rather than 10) seconds to answer each question. Participants in the Control condition again faced no time scarcity. ${ }^{1}$

To manipulate agency over scarcity, participants in the No Agency condition $(N=76)$ were not given the option to increase the time per question in the second set of questions, whereas those in the Agency condition $(N=69)$ were given the option. Specifically, we provided those in the Agency condition with the option to add four seconds per question. Participants were informed about this option before they started the second set of questions. They were allowed to exercise their agency either before starting the questions or at any point while answering them by checking a box on the screen. Importantly, however, alleviating the scarcity came at a cost: participants were told that by checking the box, they would forfeit a substantial portion (80\%) of their base payment. We added this cost to discourage participants from exercising their agency, ensuring that actual scarcity experienced by those in the Agency and No Agency conditions would be the same. Those who did choose to gain more time $(N=4)$ proceeded directly to the end of the study after completing the cognitive aptitude questions-i.e., they did not complete the dependent variable tasks. Thus, they are not included in our main analyses. As a manipulation check of our agency manipulation, after completing the 15 questions, participants were asked to indicate their perceived level of agency ( 1 to 5 scale, with higher numbers indicating greater agency).

After participants completed this task, we elicited their time preferences by asking them to allocate 100 experimental tokens across two dates (Gneezy \& Potters, 1997). Tokens allocated to later dates had higher values than tokens allocated to earlier dates, such that patience was

\footnotetext{
${ }^{1}$ See Appendix B for a replication where all participants faced the same time constraints in the first task, whereas those in the Control condition faced less (as opposed to no) scarcity in the second task.
} 
rewarded with a larger payment. Participants made two separate allocation decisions: allocating 100 tokens between "today" and "one week from today," and allocating a separate set of 100 tokens between "one week from today" and "two weeks from today." Participants were told that each token allocated to the later date ("one week from today" in the first decision, and "two weeks from today" in the second decision) would be worth $50 \%$ more than each token allocated to the earlier date. To make the choices consequential, we informed participants that one of their two allocation decisions would be randomly chosen and the corresponding amounts would be paid as a bonus on the date associated with the choice. Patience was captured by the number of tokens the participant allocated to the later date, which represented her willingness to wait for a larger, later reward over a smaller, sooner one. After making this decision, participants were given a comprehension check to test their understanding of the time preferences elicitation procedure.

Next, participants completed a set of four hypothetical risk questions that elicited a binary preference between a safer option and a riskier option (Kahneman \& Tversky, 1979). Finally, as a check of our scarcity manipulation, participants were asked to indicate the extent to which they felt they had enough time to answer the cognitive aptitude questions ( $1=I$ did not have enough time; 7 = I had too much time).

We predicted that participants in the No Agency condition would be more impatient than those endowed with agency, allocating more tokens to the earlier dates. In addition, if, as we predicted, a lack of agency affected patience through a shift in risk tolerance, the differences in intertemporal token allocations would be driven by differences in choices over risky gambles. Finally, drawing from prior literature, we predicted that those who lacked agency over their scarcity would also be more impatient than those in the Control condition, who faced no scarcity. 
Results

We report all data exclusions, all manipulations, and all measures. Only four of the 69 participants in the Agency condition chose to exercise their agency and gain more time. The remaining 65 participants faced the same time constraints as participants in the No Agency condition.

Manipulation checks confirmed that our scarcity and agency manipulations were effective at producing the intended states. Participants in both scarcity conditions answered, on average, approximately four fewer questions correctly than those in the Control condition $\left(M_{\text {ScarcityGroups }}=8.17, S E_{\text {ScarcityGroups }}=.19 ; M_{\text {Control }}=12.28, S E_{\text {Control }}=.33 ;\right.$ two-tailed pairwise ttest, $t(211)=11.715, p<.0005)$. Participants in the two scarcity conditions answered approximately the same number of questions $\left(M_{\text {Agency }}=8.31, S E_{\text {Agency }}=.27 ; M_{\text {NoAgency }}=8.05\right.$, $S E_{\text {NoAgency }}=.25$; two-tailed pairwise t-test, $\left.t(139)=-0.686, p=.49\right)$. This allows us to rule out ego depletion (Baumeister, Bratslavsky, Muraven, \& Tice, 1998) and differences in cognitive function as alternative explanations for our main results. Participants in the scarcity conditions also reported feeling significantly more time-constrained $(M=2.38, S E=.10)$ than those in the Control condition $(M=4.59, S E=.14$; two-tailed pairwise t-test, $t(209)=13.056, p<.0005)$, further suggesting our manipulation was effective in generating scarcity. Additionally, participants in the No Agency condition reported significantly lower perceived agency $(M=2.30, S E=.15)$ than those in the Control condition $(M=2.74, S E=.15$; two-tailed pairwise t-test, $t(144)=-2.087$, $p=.039)$, while reported agency of participants in the Agency $(M=2.51, S E=.16)$ and Control conditions did not differ (two-tailed pairwise t-test, $t(133)=-1.103, p=.272$ ). This suggests that 
our agency manipulation was effective as well. Finally, we find that the majority $(78 \%)$ of participants answered the time preferences comprehension check question correctly.

The proportion of tokens allocated to the earlier date did not differ between the first and second allocation decisions for any of the three treatment groups: participants made approximately the same allocation decisions when choosing between "today" and "one week from today" as when choosing between "one week from today" and "two weeks from today" (two-tailed pairwise t-tests, $p>0.05$ for all three groups). We therefore collapse across the two allocation decisions and use the number of tokens allocated to each of the two earlier dates as our primary dependent variable. Figures 1 and 2 show token allocations to the two earlier dates by condition, and Table 1 presents results from OLS regressions. Supplemental Figure 2 in Appendix $\mathrm{C}$ presents results for each allocation decision separately.

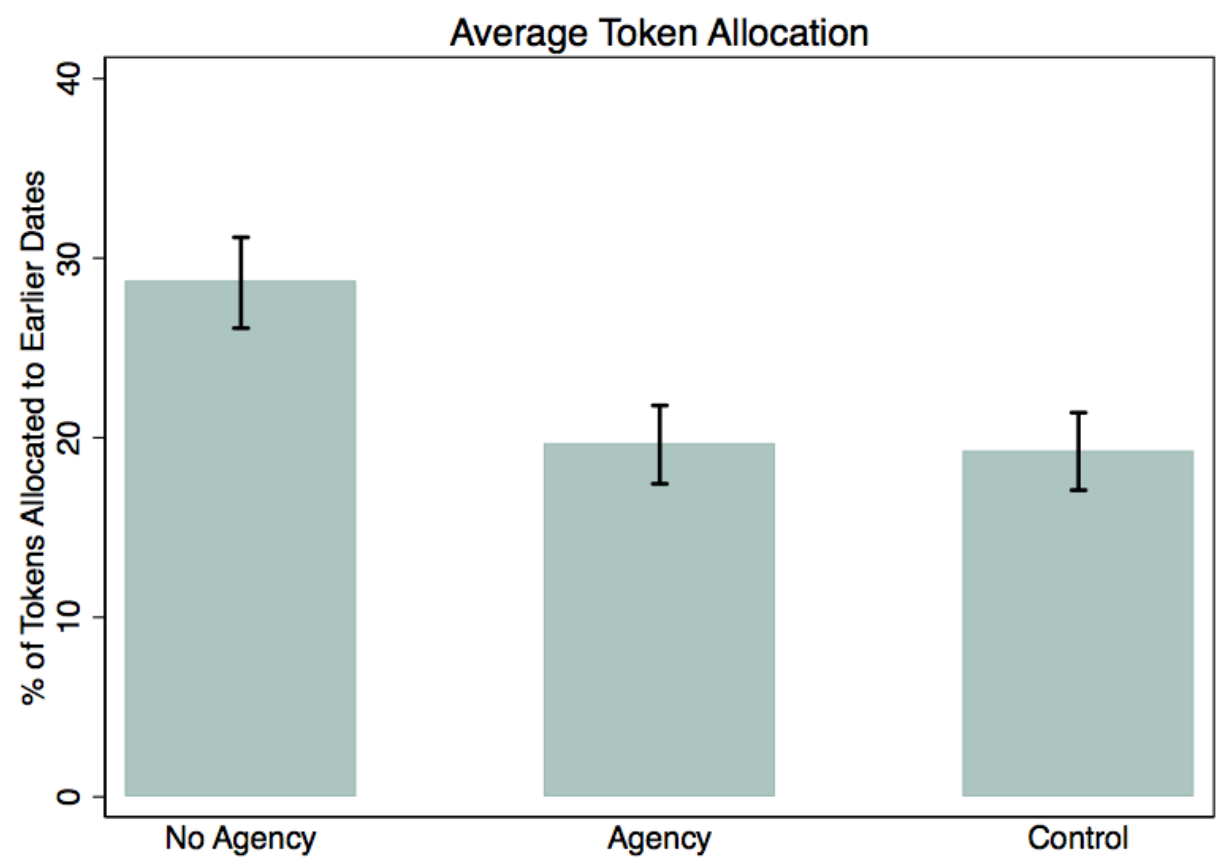

Figure 1. Study 1 results: percent of tokens allocated to earlier dates, collapsing across allocation decisions. $N=216$. Error bars denote $\pm 1 \mathrm{SE}$. 


\section{Distribution of Tokens Allocated to Earlier Dates}
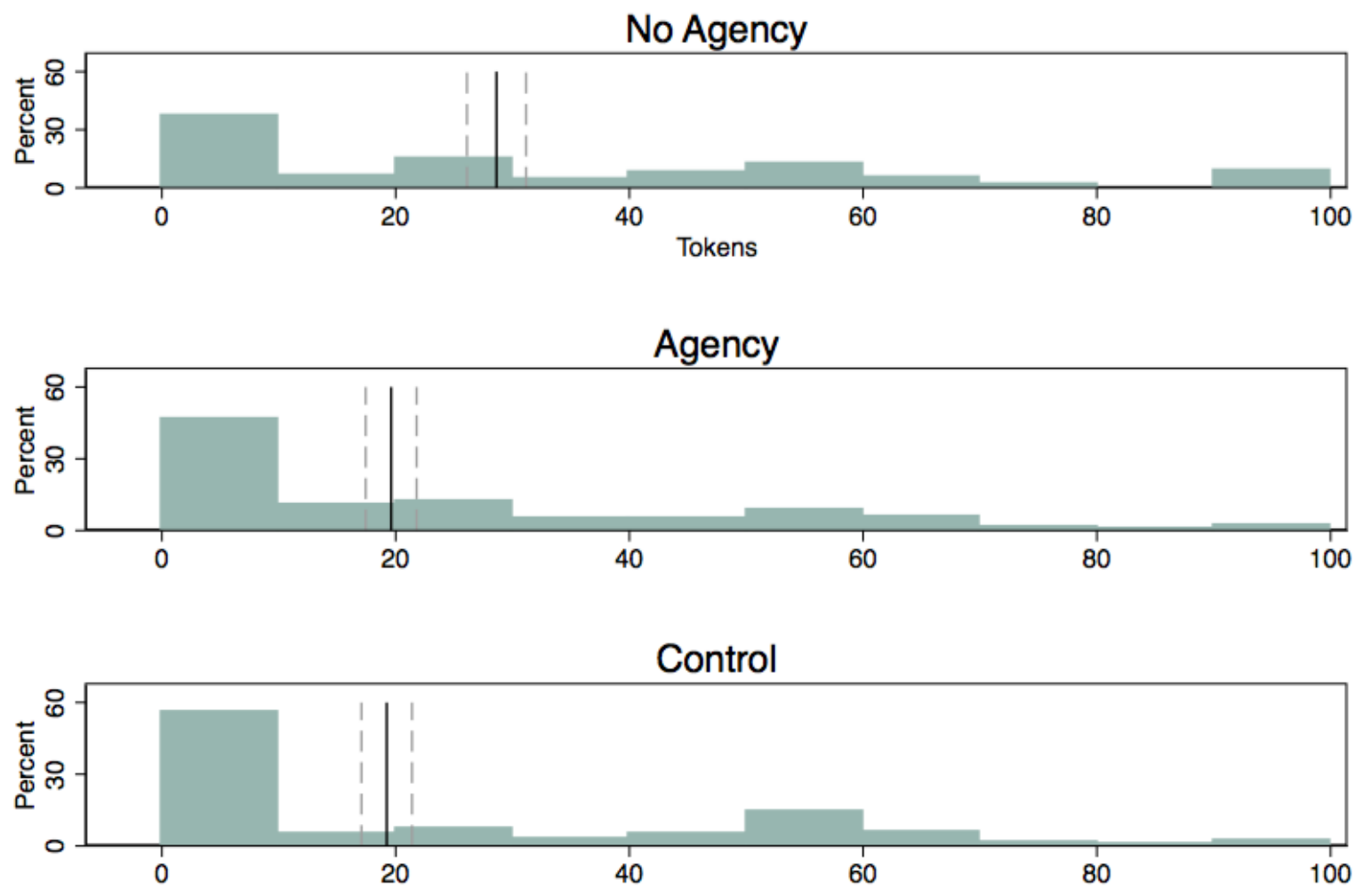

Figure 2. Study 1 results: percent of tokens allocated to earlier dates, collapsing across allocation decisions. $N=216$. Black solid line denotes mean; grey dashed lines denote $\pm 1 \mathrm{SE}$.

First, we find that participants lacking agency were substantially less patient than those who were endowed with agency, despite the fact that they faced the same level of scarcity. Participants in the No Agency condition allocated nearly 50\% more tokens to earlier dates than those in the Agency condition, thus forgoing the larger rewards from allocating tokens to the later dates (28.6 vs. 19.6 tokens; column 1 of Table 1). Second, endowing participants with agency over scarcity made their choices indistinguishable from those who did not face scarcity at all: participants in the Agency and Control conditions allocated essentially the same number of tokens to the earlier dates (19.6 vs. 19.2 tokens; columns 1 and 2). Third, consistent with the previous literature, we find that those in the No Agency condition were also substantially less 
patient than those in the Control condition (28.6 vs. 19.2 tokens; column 2). Taken together, these results show that agency fully moderated the effect of scarcity on patience.

Table 1. Study 1 results.

\begin{tabular}{lcc}
\hline & $(1)$ & $(2)$ \\
\hline No Agency & $9.0^{* *}$ & $9.4^{* *}$ \\
Agency & $(4.4)$ & $(4.3)$ \\
& & 0.4 \\
Control & & $(4.1)$ \\
& -0.4 & \\
Second token decision & $(4.1)$ & \\
& 2.1 & 2.1 \\
Constant & $(1.5)$ & $(1.5)$ \\
& $18.6^{* * *}$ & $18.2 * * *$ \\
N & $(3.0)$ & $(2.8)$ \\
R-squared & 421 & 421 \\
p-value & 0.027 & 0.027 \\
\end{tabular}

Outcome variable: number of tokens allocated to earlier dates. In (1), Agency is the omitted category. In (2), Control is the omitted category. Each participant appears in the regression twice: once for each of the two time-preferences token allocation decisions. Second token decision is a dummy variable controlling for the token allocation decision. Standard errors in parentheses. All standard errors are robust and clustered at the participant ID level. $* p<0.10, * * p<0.05, * * * p<0.01$

Having found a relationship between agency and patience, we next examined the role of risk tolerance in explaining this relationship. We measure risk tolerance by creating a variable corresponding to the proportion of times the participant chose the safer option over the riskier one in the four binary risk questions, with greater values corresponding to greater risk aversion. Comparing the two scarcity conditions, we use OLS with robust standard errors to regress the risk-tolerance variable on a dummy variable for the No Agency condition. This analysis reveals that individuals who lacked agency over scarcity were significantly more likely to choose the 
safe option than those with agency $(B=.13, S E=.05 ; p=.006)$. Regressing token allocation on both the experimental-condition dummy and the risk variable shows that participants' responses to the risk measures largely explain the observed relationship between agency and token allocation. In particular, while lower risk tolerance is associated with allocating a greater number of tokens to earlier dates (OLS with robust SE clustered at the participant ID level when including only scarcity groups: $B=23.63, S E=6.83, p=.001$; OLS with robust SE clustered at the participant ID level when including all three treatment groups: $B=20.37, S E=5.30 ; p<.0005$ ), the coefficient on the experimental-condition dummy changes from being significant when the risktolerance variable is not included (OLS with robust SE clustered at the participant ID level, $B=9.02, S E=4.38 ; p=.041)$ to being non-significant when it is included (OLS with robust SE clustered at the participant ID level, $B=6.23, S E=4.41 ; p=.160)$. Approximately $30 \%$ of the effect generated by a lack of agency on patience can be attributed to the indirect effect on risk tolerance.

Combined, the results of Study 1 provide direct evidence for our hypotheses: a lack of agency decreases tolerance for risk, which in turn leads to greater impatience.

\section{Study 2}

Our second study examined whether the observed relationship between personal agency and patience generalizes to contexts other than scarcity. Specifically, we tested whether increased agency could moderate the effect of environmental stressors on behavior.

\section{Methods}

This experiment was approved by the University of California, San Diego, IRB. It complied with all relevant ethical regulations and involved informed consent. Individuals 
$(N=115)$ participated in a laboratory experiment in exchange for class credit. In operationalizing an adverse state, we built on a classic helplessness paradigm (Alloy \& Abramson, 1982) that exposed participants to environmental stressors in the form of aversive, unpredictable noise. All participants were told they would be asked to solve 30 anagrams in five minutes while listening to a loud, jarring noise $\left(3,000 \mathrm{~Hz}, 90 \mathrm{~dB}\right.$ tone at random intervals) through a set of headphones. ${ }^{2}$ We provided them with examples of anagrams (e.g., TIGF is an anagram for GIFT) and told each participant that at the end of the study, we would randomly choose one in 10 participants to receive a $\$ 20$ bonus.

Participants were instructed to put on the headphones that were connected to their computer. They were then randomized into either the Agency or No Agency condition. Participants in the No Agency condition were told that removing the headphones would disqualify them from the study, and thus from the possibility of receiving the bonus payment. In contrast, participants in the Agency condition were told that they had the option to remove the headphones at any time, but that doing so would cost them $50 \%$ of the potential bonus payment. Similar to Study 1, we added this cost to discourage participants from exercising their agency, ensuring that those in the Agency and No Agency conditions experienced the same level of adversity. Participants completed four practice anagrams before beginning the real anagram task.

Immediately after the anagram task, we elicited participants' levels of patience by asking them to make a series of 27 hypothetical choices between a smaller, sooner reward and a larger, later reward (e.g., "Would you prefer \$14 today or \$25 19 days from now). The smaller (sooner) amount, the larger (later) amount, and the delay between the payouts varied across questions, allowing us to estimate patience using both non-parametric and parametric techniques (Kirby, Petry, \& Bickel, 1999).

\footnotetext{
${ }^{2}$ Please see Appendix A for detailed instructions and information on the aversive noise.
} 
We predicted that those who had greater agency - that is, those who had the option to remove the headphones - would exhibit greater patience relative to those who did not have this option. Specifically, we hypothesized that participants in the Agency condition would be more willing to wait for larger, later rewards than those in the No Agency condition, despite being exposed to the same level of adversity.

Results

Two participants (both in the Agency condition) removed their headphones during the experiment and are thus not included in the analysis. In addition, we exclude four participants for always choosing either the first (smaller-sooner) or second (larger-later) reward across all 27 time-preferences questions, as such responses yield unrationalizable time preferences. Including these six participants in the analyses does not qualitatively change the results (all $p s<=.018$ ). ${ }^{3}$

We are left with 109 participants $\left(N_{\text {NoAgency }}=52 ; N_{\text {Agency }}=57\right)$ in our final analysis.

Participants in both groups solved on average the same number of anagrams $\left(M_{\text {NoAgency }}=6.25\right.$, $S E_{\text {NoAgency }}=.59 ; M_{\text {Agency }}=5.16, S E_{\text {Agency }}=.44$; pairwise t-test, $\left.p=.136\right)$.

Despite being exposed to the same level of noise, participants in the Agency condition made significantly more patient choices than those in the No Agency condition. In particular, they chose the smaller, sooner reward on average $50 \%$ of the time $(S E=2 \%)$, whereas those in the No Agency condition chose it $61 \%$ of the time ( $S E=2 \%$; OLS with robust SE, $p=.001$; MannWhitney $U$ test, $p=.009)$. See Figures 3 and 4.

\footnotetext{
${ }^{3}$ It is not possible to include the four participants with unrationalizable time preferences in the parametric analysis.
} 


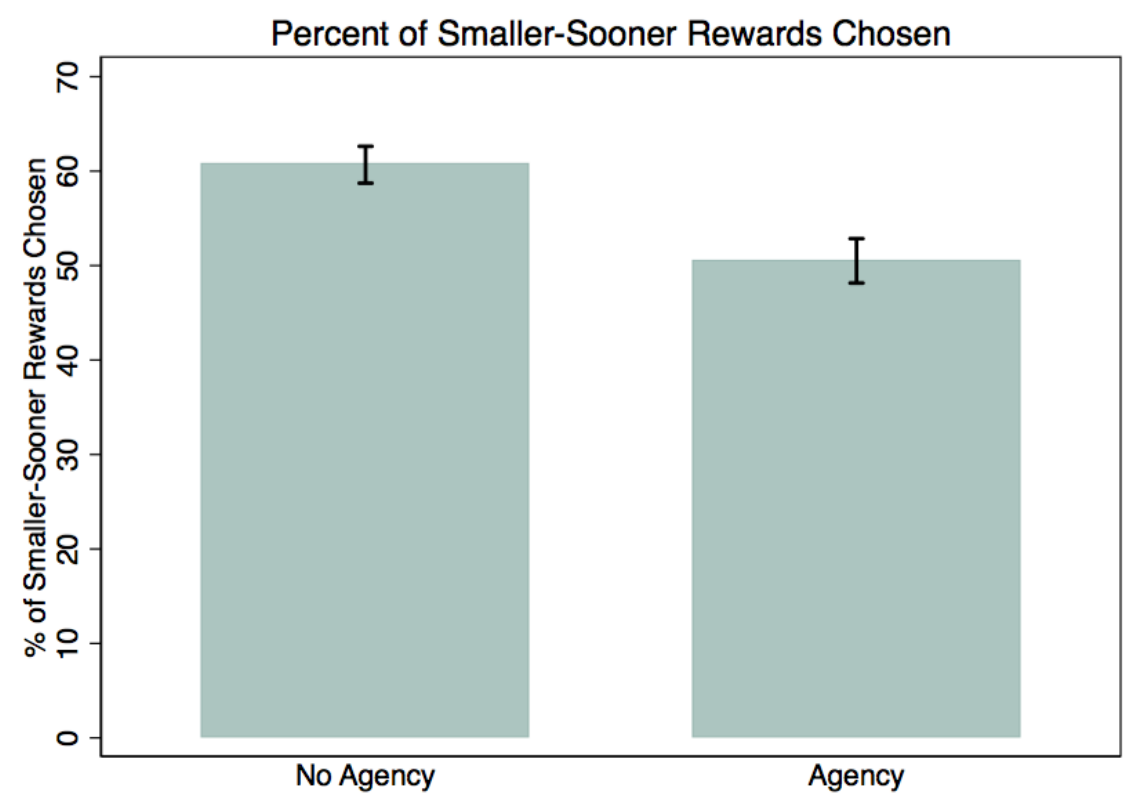

Figure 3. Study 2 results: percent of smaller-sooner rewards chosen, by treatment group. $N=109$. Error bars denote $\pm 1 \mathrm{SE}$.

\section{Distribution of Smaller-Sooner Rewards Chosen}
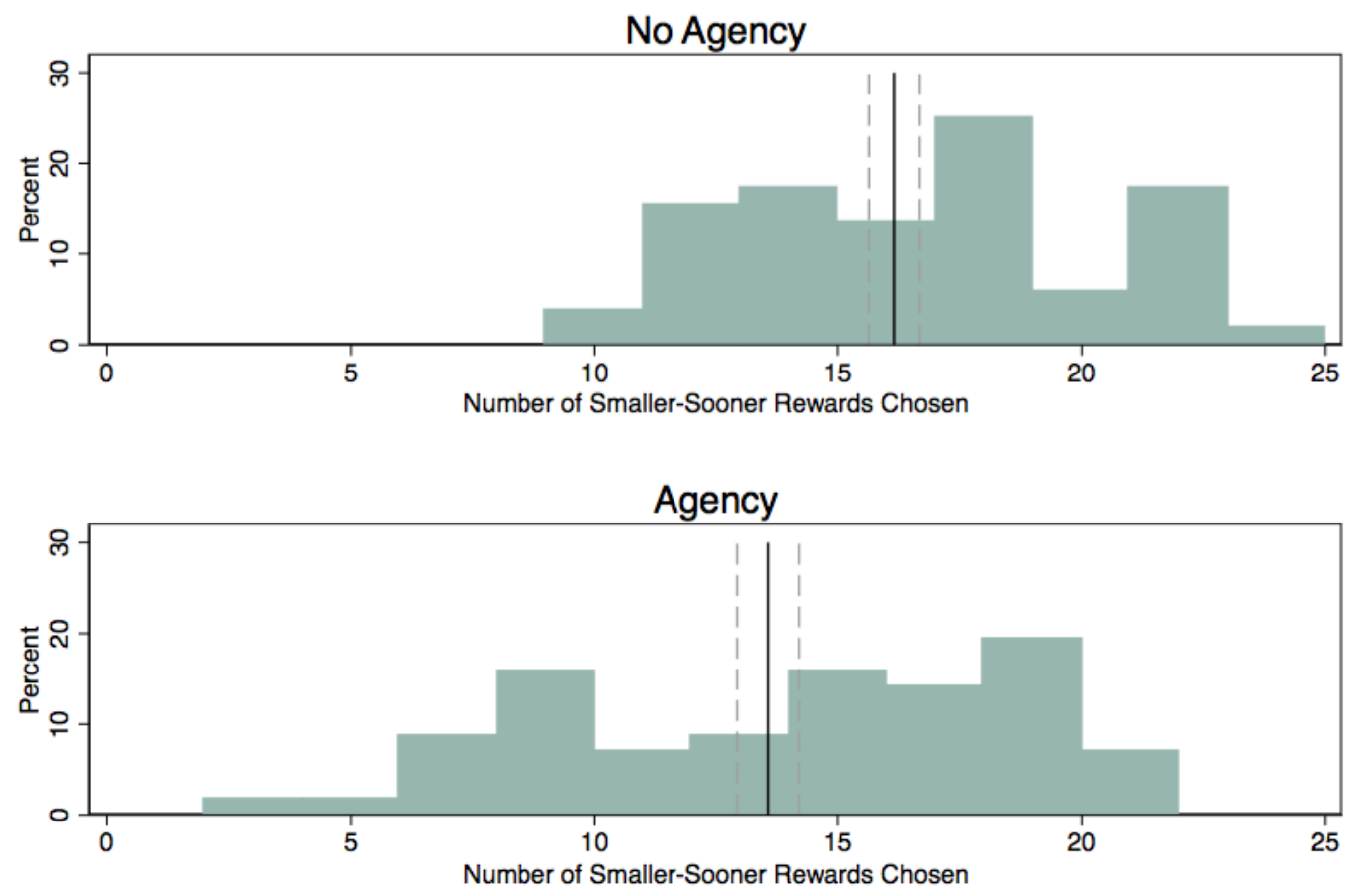

Figure 4. Study 2 results: distribution of smaller-sooner rewards chosen, by treatment group. $N=109$. Black solid line denotes mean; grey dashed lines denote $\pm 1 \mathrm{SE}$. 
We next used participants' responses to the 27 time-preference questions to identify each individual's indifference point between smaller, sooner rewards and larger, later ones. This step allowed us to estimate the discount parameter $k$ of the hyperbolic discounting formula:

$$
V=\frac{A}{1+k D}
$$

where $D$ is the delay in days, $A$ is the delayed reward, and $V$ is the present value of the delayed reward. ${ }^{4}$ The indifference point provides the values of the present gain $V$ that makes an individual indifferent between receiving $V$ now or a delayed gain $A$ at point $D$ days in the future. Using these data points, we can solve for the discounting parameter $k$, where a larger $k$ corresponds to greater myopia and impatience (Kirby, Petry, \& Bickel, 1999; Hardisty \& Weber, 2009; Kirby \& Petry, 2004). Consistent with the non-parametric results, the mean discounting parameter $k$ of participants in the No Agency condition $(M=.015, S E=.003)$ was significantly higher than that of the Agency condition participants $(M=.007, S E=.001$; two-tailed pairwise ttest, $t(107)=2.727, p=.008)$.

The results of Study 2 are consistent with those obtained in Study 1: participants lacking agency over their adverse state made less patient choices than those who had agency over the same state.

\section{General Discussion}

In this paper, we show that personal agency over one's environment has a significant impact on preferences. Our first study demonstrates that people who have agency over resource (time) scarcity make significantly more patient decisions than those who lack agency over scarcity. In fact, people with agency appeared just as patient as those who did not experience

\footnotetext{
${ }^{4}$ Prior work has shown that this model of hyperbolic discounting provides a good fit for intertemporal choice (Frederick, Loewenstein, \& O’Donoghue, 2002).
} 
scarcity at all. Importantly, we observed this effect even though individuals endowed with greater agency did not exercise it, meaning they faced the exact same scarcity as those with no agency. Further, we show that the effects of agency on intertemporal choice are driven by changes to individuals' risk tolerance. Considered in the context of recent work examining the effects of scarcity on decision-making, our findings point to a distinct pathway through which exposure to resource scarcity may affect behavior - namely, through the channel of personal agency (Mullainathan \& Shafir, 2013; Shah, Mullainathan, \& Shafir, 2012).

In our second study, we demonstrate that the effects of agency observed in Study 1 extend to other adverse states such as exposure to environmental stressors. Here, people who had agency over an aversive noise were more likely to make patient decisions than those who lacked the option, despite the fact that they did not utilize this option and faced the same environment.

Our findings have significant implications for policies aimed at alleviating poverty, suggesting an approach that differs substantially from those prescribed by existing theories. For example, the structural theory of poverty (Rank, Yoon, \& Hirschl, 2003) argues one could mitigate persistent poverty by increasing the poor's access to institutions and lifting discriminatory practices. From a practical standpoint, this approach emphasizes the importance of increasing access and opportunities. Another, rather distinct approach to thinking about the poor is offered by the "culture of poverty" theory (Banfield, 1970; Lewis, 1970), which contends that people in a state of scarcity have immutable, "deviant" preferences that would dampen the effectiveness of such policies.

In documenting the powerful effects of agency on behavior, our findings point to a different approach: structuring programs to provide individuals with greater agency. In addition to any instrumental or intrinsic benefits of agency, our results suggest such programs could lead 
to more farsighted behavior. This shift could increase the likelihood that program participants engage in behaviors associated with immediate costs and larger, delayed rewards, such as investing in education and saving for a rainy day. Note that because, in our studies, increased agency shifted behavior even when the agency was not exercised, agency-based interventions have the potential to "nudge" more patient choices (Thaler \& Sunstein, 2008) while keeping program costs relatively low. 


\section{References}

1. Rawls, J. A Theory of Justice. Harvard University Press. (1971).

2. Berlin, I. Two concepts of liberty. Berlin, I, 118, 172. (1969).

3. Marx, K., Engels, F. The German Ideology. New York: International Publishers. (1947).

4. Friedman, M., Friedman, R. Free to choose: A personal statement. Houghton Mifflin Harcourt. (1990).

5. Sen, A. Freedom of Choice: Concept and Content. European Economic Review. 32, 269294. (1988).

6. Brehm, J. W. A theory of psychological reactance. Oxford, England: Academic Press. (1966).

7. Carter, I. The independent value of freedom. Ethics 105(4), 819-845. (1995).

8. Landau, M. J., Kay, A. C., Whitson, J. A. Compensatory control and the appeal of a structured world. Psych Bull 141(3), 694. (2015).

9. Langer, E. J. The psychology of control. Beverly Hills: Sage Publications. (1983).

10. Falk, A., Kosfeld, M. The hidden costs of control. Am Econ Rev 96(5), 1611-1630. (2006).

11. Gneezy, A., Imas, A., Ariely, D. Taking Control: The Role of Helplessness in Negative Reciprocity. (2016).

12. Langer, E. J., Rodin, J. The Effects of choice and enhanced personal responsibility for the aged: A field experiment in an institutional setting. J Personality Social Psych 34(2), 191-198. (1976).

13. Schulz, R. Effects of control and predictability on the physical and psychological wellbeing of the institutionalized aged. J Personality Social Psych 33(5), 563-573. (1976). 
14. Crisp, B. R., Barber, J. G. The effect of locus of control on the association between risk perception and sexual risk-taking. Personality Indiv Diff 19(6), 841-845. (1995).

15. Nordgren, L. F., Van Der Pligt, J., Van Harreveld, F. Unpacking perceived control in risk perception: The mediating role of anticipated regret. J Behav Decision Making 20(5), 533-544. (2007).

16. Langer, E. J. The illusion of control. J Personality Social Psych 32(2), 311-328. (1975).

17. Dasgupta, P., Maskin, E. Uncertainty and hyperbolic discounting. Am Econ Rev 95(4), 1290-1299. (2005).

18. Epper, T., Fehr-Duda, H., Bruhin, A. Viewing the future through a warped lens: Why uncertainty generates hyperbolic discounting. J Risk Uncertainty 43(3), 169-203. (2011).

19. Halevy, Y. Strotz meets Allais: Diminishing impatience and the certainty effect. Am Econ Rev 98(3), 1145-1162. (2008).

20. Inglehart, R., et al (eds) Data from "World Values Survey: Round Six - Country Pooled Datafile Version.” http://www.worldvaluessurvey.org/WVSDocumentationWV6.jsp (2014).

21. Lynch, J. G., Jr, Zauberman, G. When do you want it? Time, decisions, and public policy. J Pub Policy Marketing 25(1), 67-78. (2006).

22. Laibson, D. Golden eggs and hyperbolic discounting. Quarterly J Econ 112(2), 443-478. (1997).

23. Dohmen, T., et al. Individual risk attitudes: Measurement, determinants, and behavioral consequences. J Eur Econ Assn 9(3), 522-550. (2011).

24. Carvalho, L. S. Poverty and time preferences. Mimeo. (2010). 
25. Lawrance, E. C. Poverty and the rate of time preference: Evidence from panel data. $J$ Political Econ 99, 54-77. (1991).

26. World Health Organization. Tobacco and poverty: a vicious circle. (WHO Publication WHO/NMD/TFI/04.01;

www.who.int/tobacco/communications/events/wntd/2004/en/wntd2004_brochure_en.pdf ). (2004). Accessed 9 July 2018.

27. Haushofer, J., Fehr, E. On the psychology of poverty. Science 344(862), 862-867. (2014).

28. Mullainathan, S., Shafir, E. Scarcity: Why Having Too Little Means So Much. Time Books Henry Holt and Company, LLC, New York, NY. (2013).

29. Guiso, L., Paiella, M. Risk aversion, wealth, and background risk. J Eur Econ Assn 6(6), 1109-1150. (2008).

30. Haushofer, J., Schunk, D., Fehr, E. Negative income shocks increase discount rates Mimeo. (2013).

31. Shah, A., Mullainathan, S., Shafir, E. Some consequences of having too little. Science 338, 682-685. (2012).

32. Aizer, A., Eli, S., Ferrie, J., Lleras-Muney, A. The Long-run impact of cash transfers to poor families. Am Econ Rev 106(4), 935-971. (2016).

33. Gneezy, U., Potters, J. An Experiment on risk taking and evaluation periods. Quarterly J Econ 112(2), 631- 645. (1997).

34. Kahneman, D., Tversky, A. Prospect theory: An analysis of decision under risk. Econometrica 47(2), 263-292. (1979).

35. Baumeister, R. F., Bratslavsky, E., Muraven, M., Tice, D. M. Ego depletion: Is the active self a limited resource? J Personality Social Psych 74(5), 1252-1265. (1998). 
36. Alloy, L. B., Abramson, L. Y. Learned helplessness, depression, and the illusion of control. J Personality Social Psych 42(6), 1114-1126. (1982).

37. Kirby, K. N., Petry, N. M., Bickel, W. K. Heroin addicts have higher discount rates for delayed rewards than non-drug-using controls. J Exp Psych: General 128(1), 78-87. (1999).

38. Frederick, S., Loewenstein, G., O’Donoghue, T. Time discounting and time preference: a critical review. J Econ Lit 40(2), 351-401. (2002).

39. Hardisty, D. J., Weber, E. U. Discounting future green: money versus the environment. $J$ Exp Psych: General 138(3), 329-340. (2009).

40. Kirby, K. N., Petry, N. M. Heroin and cocaine abusers have higher discount rates for delayed rewards than alcoholics or non-drug-using controls. Addiction 99(4), 461-471. (2004).

41. Rank, M. R., Yoon, H. S., Hirschl, T. A. American poverty as a structural failing: Evidence and arguments. J Soc \& Soc Welfare, 30(4), 3-29. (2003).

42. Banfield, E. The Unheavenly City, Boston: Little, Brown \& Co., 125. (1970).

43. Lewis, O. Anthropological Essays, New York: Random House. (1970).

44. Thaler, R. H., Sunstein, C. Nudge: Improving Decisions About Health, Wealth, and Happiness. (2008). 


\section{Author Contributions}

All authors developed the theoretical framework and study concepts equally. A. Jaroszewicz collected data for Study 1 and A. Imas collected data for Study 2. Each author was involved in the data analysis. All authors contributed to the drafting and editing of the manuscript. 


\section{Appendix A: Supplemental Materials}

\section{0-2014 World Values Survey Questions}

Question 55: Some people feel they have completely free choice and control over their lives, while other people feel that what they do has no real effect on what happens to them. Please use this scale where 1 means 'none at all' and 10 means 'a great deal' to indicate how much freedom of choice and control you feel you have over the way your life turns out.

Question 229: Are you employed now or not? If yes, about how many hours a week? If more than one job: only for the main job:

- Full time employee (30 hours a week or more)

- Part time employee (less than 30 hours a week)

- Self employed

$\circ$ Retired/pensioned

- Housewife not otherwise employed

- Student

- Unemployed

○ Other (write in)

Question 237: During the past year, did your family:

- Save money

○ Just get by

- Spent some savings [sic]

- Spent savings and borrowed money [sic] 


\section{Study 1 Instructions}

(Manipulations - orange font pertains to Control group, dark blue font pertains to groups experiencing scarcity [No Agency and Agency], red font pertains to Agency group.)

\section{Instructions}

You will be given 15 True-False questions to answer. Your payment will depend partly on your answers to these questions.

You will begin with 50 cents. For each question you answer correctly, you will be paid 2 additional cents. You will earn no additional money if you answer incorrectly or don't answer the question at all.

[You will have as much time as you need to answer each question. After you answer each question, you will see whether you got the answer right or wrong.] [You will have 10 seconds to answer each question. After the 10 seconds are over, you will see whether you got the answer right or wrong. The screen will then automatically advance to the next question.]

The questions will begin when you click on the ">>" button below.

(Next page. Each of the 15 questions below had the options "True" and "False" and appeared on its own page for either 10 seconds [for the groups experiencing scarcity, i.e. No Agency and Agency] or for an unlimited period of time [for the Control group]. A large green checkmark appeared after correct answers were chosen, while a large red X appeared after an incorrect answer, or no answer, was chosen. The feedback remained on the screen for two seconds before the screen automatically advanced to the next question.)

There are ten letters in the word COMMITMENT.

Emma drives 10 miles to work and back every work day, and 2 miles to the gym and back on each day of the weekend. She drives for 54 miles every week.

John and Mary have bicycles. Their little sister Elizabeth has a tricycle. If they all go out for a ride, they have six wheels altogether.

The letters in the word "Chimney" are in alphabetical order.

The sister of your brother's father is your aunt.

There are only two vowels in each of the following names: Emma, Adam, Emil, Nathan, Eli.

The combination of two of the numbers: $1,3,4,7,8$ is equal to 13 .

Roy smokes a pack of cigarettes every three days. He smokes seven packs every three weeks. 
A farmer had 17 sheep. All but 9 died. There are 36 feet on the remaining sheep.

The word FEEL can be formed with exactly 12 match sticks without bending or breaking any of them.

A number of children are standing a circle. They are evenly spaced and the 8th child is directly facing the 16th child. There are 17 children in the circle.

Lucy made three steps to the North, after that she took a step to the East and three more steps to the South. She is now at her starting position.

Each child in a family has at least 5 brothers and 3 sisters. The smallest number of children the family might have is 10 .

The word VILE can be written using four of the letters of the word VIOLATES.

If you write down all the numbers from 1 to 25 , every two numbers following one another will add up to an odd number.

(Next page.)

You will now be presented with 15 more questions. Once you are finished with the questions, we will randomly choose a number between 1 and 15 . If the number of questions you answer correctly is at least as big as that number, you will receive 50 cents. Otherwise, you will receive no additional payment. The more questions you answer correctly, the higher your chances of being paid.

[You will have as much time as you need to answer each question.] [In addition, you will only have 6 seconds instead of 10 seconds to answer each question.]

(Next page)

You have been given the control to gain an additional 4 seconds per question in exchange for paying a portion of your baseline fee (40 cents). If you choose to exercise this option, you will have 10 seconds per question. Instead of receiving 50 cents as your baseline fee, you will receive 10 cents and whatever you earn for answering the questions.

To pay 40 cents for an additional 4 seconds per question, check the box below. Otherwise, just click the ">>" button at the bottom of the screen to begin.

Note that if you choose not to pay now, you will continue having the control to do so after starting the questions, as well.

The questions will begin when you click on the ">>" button below. 


\section{Yes, I would like to pay 40 cents in exchange for an additional 4 seconds per question}

(Next page. Each of the 15 questions below had the options "True" and "False" and appeared on its own page. Those in the conditions experiencing scarcity [No Agency and Agency] saw each question for only six seconds, while those in the Control condition saw each question for as long as they wanted. Those in the Agency group also saw the option in red font. If they clicked the box, all questions thereafter remained visible for four seconds longer and the sentence in red disappeared. As before, a green checkmark appeared after correct answers, and a red X appeared after incorrect or blank answers.)

13 minutes after 5 o'clock is exactly 47 minutes before 6 o'clock.

$\square$ I would like to pay 40 cents in exchange for an additional 4 seconds per question for all questions that follow.

The word AMITY is written by using the first letters of the sentence "A mouse in the yard". I would like to pay 40 cents in exchange for an additional 4 seconds per question for all questions that follow.

If Peter looks at a mirror and touches his left ear, his mirror image would touch his right ear. $\square$ I would like to pay 40 cents in exchange for an additional 4 seconds per question for all questions that follow.

Using exactly three colors you can paint the sides of a cube so that sides of the same color will never touch.

I would like to pay 40 cents in exchange for an additional 4 seconds per question for all questions that follow.

The third vowel in this sentence is "o".

I would like to pay 40 cents in exchange for an additional 4 seconds per question for all questions that follow.

Seven chickens and two cats have twenty-two legs among them.

$\square$ I would like to pay 40 cents in exchange for an additional 4 seconds per question for all questions that follow.

There are four letters between the letter $\mathrm{K}$ and the letter $\mathrm{P}$ in the alphabet.

$\square$ I would like to pay 40 cents in exchange for an additional 4 seconds per question for all questions that follow.

If the word ERA is written below the word ANT and the word RAT is written below ERA, then the word ART will form diagonally.

$\square$ I would like to pay 40 cents in exchange for an additional 4 seconds per question for all questions that follow. 
.55 hours added to half an hour is exactly 85 minutes.

$\square$ I would like to pay 40 cents in exchange for an additional 4 seconds per question for all questions that follow.

If Tuesday is the second day of the month, then the first Sunday will be the sixth day of the month.

$\square$ I would like to pay 40 cents in exchange for an additional 4 seconds per question for all questions that follow.

62 is the next logical number in the sequence: $2,6,14,30$

$\square$ I would like to pay 40 cents in exchange for an additional 4 seconds per question for all questions that follow.

Statement 1: The boy plays baseball. Statement 2: All baseball players wear hats. Statement 3: The boy wears a hat. Assume the first 2 statements are true. The final one is:

$\square$ I would like to pay 40 cents in exchange for an additional 4 seconds per question for all questions that follow.

A train travels 20 feet in $1 / 5$ second. At this same speed, the train will travel 60 feet in three seconds.

$\square$ I would like to pay 40 cents in exchange for an additional 4 seconds per question for all questions that follow.

A boy is 17 years old and his sister is twice as old. When the boy is 23 years old, his sister is 40 years old.

$\square$ I would like to pay 40 cents in exchange for an additional 4 seconds per question for all questions that follow.

If you rearrange the letters ANICH you will get the name of a country.

$\square$ I would like to pay 40 cents in exchange for an additional 4 seconds per question for all questions that follow.

(Next page. Questions were answered on a scale from 1 [Not at all] to 5 [Very]. Participants who chose to gain more time were sent straight to the demographic questions.)

Please indicate to what extent you feel...

Angry

Happy

Empowered

Sad

(Next page)

\section{Instructions}


In the next section, you will be asked to make two decisions about how to divide a set of 100 tokens between two dates. Your earnings will depend on these choices.

The tokens you allocate to the later date will always be worth more money than the tokens you allocate to the earlier date. This process is best described by an example.

The decision on the screenshot below shows the choice to allocate 100 tokens between two dates: today, and tomorrow. In this decision, each token you allocate to today is worth $\$ 0.10$, while each token you allocate to tomorrow is worth $\$ 0.20$.

So, if you allocate 80 tokens to today and 20 tokens to tomorrow, the value of the tokens is $80 \mathrm{x}$ $\$ 0.10=\$ 8.00$ today, and $20 \times \$ 0.20=\$ 4.00$ tomorrow.

On the other hand, if you allocate 20 tokens to today and 80 tokens to tomorrow, the value of the tokens is $20 \times \$ 0.10=\$ 2.00$ today, and $80 \times \$ .20=\$ 16.00$ tomorrow.

Please remember that your earnings will depend on your responses to these questions. One of your choices will be randomly chosen and on the specified date, you will be given a bonus equal to $1 / 100$ of the value you allocate to that date.

Please allocate your 100 tokens across these two choices. Remember that the allocations in each row must sum to 100.
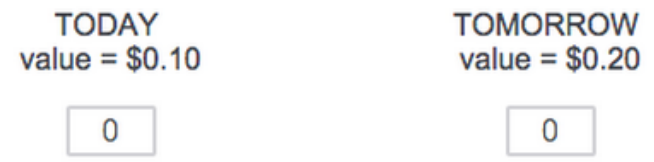
Total

EXAMPLE CHOICE

(Next page. Total automatically calculated. Participants could not proceed if the total did not equal 100.) 
Please allocate your 100 tokens across these two choices. Remember that the allocations in each row must sum to 100.

\begin{tabular}{lcccc} 
& $\begin{array}{c}\text { TODAY } \\
\text { value }=\$ 0.20\end{array}$ & $\begin{array}{c}\text { IN ONE WEEK } \\
\text { value }=\$ 0.30\end{array}$ & Total \\
Choice 1 & 0 & 0 & 0 \\
\hline
\end{tabular}

Please allocate your 100 tokens across these two choices. Remember that the allocations in each row must sum to 100 .

IN ONE WEEK
value $=\$ 0.20$

Choice 2

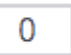

IN TWO WEEKS

value $=\$ 0.30$

0
Total

0

(Next page)

Suppose the values of the tokens are $\$ 0.20$ for today and $\$ 0.30$ one week from now. If you allocate 50 tokens to today and 50 tokens to one week from now, what is the value of the tokens (before we divide them by 100)?

○ \$10 today and $\$ 20$ in one week

- $\$ 10$ today and $\$ 15$ in one week

○ \$20 today and $\$ 30$ in one week

(Next page)

For the following sets of gambles, please choose the gamble that you would prefer. 
Please choose between the following gambles:

$\$ 2,500$ with probability .33

$\$ 2,400$ with probability .66

$\$ 0$ with probability .01

$\$ 2,400$ with certainty

$\mathrm{O}$

Please choose between the following gambles:

$\$ 2,500$ with probability .33

$\$ 0$ with probability .67

$\mathrm{O}$

Please choose between the following gambles:

$\$ 4,000$ with probability .80

$\$ 0$ with probability .20

$\mathrm{O}$

Please choose between the following gambles:

$\$ 4,000$ with probability .20

$\$ 0$ with probability .80
$\$ 2,400$ with probability .34

$\$ 0$ with probability .66

$\mathrm{O}$

$\$ 3,000$ with certainty

$\mathrm{O}$

$\$ 3,000$ with probability .25

$\$ 0$ with probability .75

(Next page. 7-point scale ranging from "I did not have enough time" to "I had too much time")

Did you have enough time to answer the timed true-false questions earlier in the survey?

(Next page)

Gender

- Male

○ Female

Race

○ White

- Black or Africa American

○ Hispanic (non-white)

- Asian

- Other/ mix

- Prefer not to answer

Are you fluent in English?

o No 
○ Yes

Are you a student?

○ No

○ Yes

What is your annual income, after taxes and deductions?

○ $0-\$ 10,000$

- $\$ 10,000-\$ 20,000$

- $\$ 20,000-\$ 40,000$

○ $\$ 40,000-\$ 60,000$

○ $\$ 60,000-\$ 80,000$

- $\$ 80,000-\$ 100,000$

○ $\$ 100,000-\$ 150,000$

○ over $\$ 150,000$

(Next page. Text box.)

Finally, we'd like to ask you on your thoughts about the experiment. Did anything seem unusual or unclear? Did you run into any difficulties?

(Next page. Font in purple appeared only for individuals who did not choose to gain more time. Time periods in curly brackets dependent on which time preferences question was chosen to be realized. Font in green appeared only for individuals who chose to gain more time.)

Thank you for your time! Your responses have been recorded and the experiment is now over.

You began with 50 cents. In the first set of questions, you answered [\#] questions correctly, where each question was worth 2 cents. In the second set of questions, you answered [\#] questions correctly, for a total of [\$]. You also earned a bonus payment of [\$] today \{in one week \} and $[\$]$ in one week in two weeks $\}$. You chose to pay 40 cents of your baseline fee to gain an additional 4 seconds of time per question.

Thus, altogether, your earnings are: [\$].

Please proceed to the next screen to receive your Mechanical Turk completion code. 


\section{Study 2 Instructions}

\section{Instructions (for No Agency condition)}

Welcome to our experiment. To thank you for your participation, we will randomly choose 1 in 10 participants to receive $\$ 20$. If you are chosen to be paid, we will notify you by email and pay you next week.

Please put on the headphones located at your station.

The aim of the first part of the experiment is to examine how environmental factors impact performance in simple word tasks. You will be asked to solve a series of anagrams. Anagrams are words with the letters jumbled.

For example:

TIGF is an anagram for GIFT

LERU is an anagram for RULE

UMOSE is an anagram for MOUSE

You will be given 30 anagrams, and asked to solve as many as possible in 5 minutes. The solution to each anagram is a very well known word (not a person's name), and each anagram has only one such solution.

Importantly, while solving the anagrams you may be exposed to noise through your headphones. Note that removal of the headphones at any point will disqualify you from the study, which means you will not be eligible to be paid.

\section{Instructions (for Agency condition)}

Welcome to our experiment. To thank you for your participation, we will randomly choose 1 in 10 participants to receive $\$ 20$. If you are chosen to be paid, we will notify you by email and pay you next week.

Please put on the headphones located at your station.

The aim of the first part of the experiment is to examine how environmental factors impact performance in simple word tasks. You will be asked to solve a series of anagrams. Anagrams are words with the letters jumbled.

For example:

TIGF is an anagram for GIFT

LERU is an anagram for RULE

UMOSE is an anagram for MOUSE

You will be given 30 anagrams, and asked to solve as many as possible in 5 minutes. The solution to each anagram is a very well known word (not a person's name), and each anagram has only one such solution.

Importantly, while solving the anagrams you may be exposed to noise through your headphones. Note that you can choose to remove your headphones at any point during the experiment at a cost of $50 \%$ of your payment should you be chosen to get paid. That is, if you choose to remove your headphones, half of your final payment will be deducted if you are chosen to be paid.

(Next page)

Please proceed to the next page to practice solving anagrams while being exposed to noise. 
(Next page)

WHYROT

LOMUVE

MILTEY

CLAUHN

(Next page)

Please inform the experimenter NOW if you have any questions.

Otherwise, please proceed to the next page and begin solving the anagrams.

(Next page)

Solve as many anagrams as you can. Enter your solution into the Text Box below each word. You have 5 minutes.

(While solving the anagram task, participants listened to a loud, jarring noise $[3,000 \mathrm{~Hz}, 90 \mathrm{~dB}$ tone at random intervals]. Recordings of the noise are available at https://sites.google.com/site/alexoimas/Unpredictable_3.mp3.)

\section{MEECHS}

INGALC

IBINIK

CERAPH

PIRAMI

CLINEP

NERCRO

AHVEBE

PRINGY

ROTHEY

TACTIN

URAUBE

WHOSAD

ASHRIP

JEERTS

YOUTCH

SPOMIE

DANINL

ENGLOB

POWNEA

HEHRST

MODDEO

CIRPAY

GIRONI

DILQUI 
TORFOG

GOAUNT

RELPHE

DORPAY

LENZOZ

(Next page)

You will now be presented with a series of 27 choices. Please take the choices seriously, and make each decision as though it will actually be carried out. In each case, you will be presented with a choice between an immediate reward and a delayed reward. Please choose the one you would prefer.

Would you prefer $\$ 54$ dollars today or $\$ 55$ dollars 117 days from now?

○ \$54 dollars today

○ \$55 dollars 117 days from now

Would you prefer $\$ 55$ dollars today or $\$ 75$ dollars 61 days from now?

○ \$55 dollars today

- \$75 dollars 61 days from now

Would you prefer $\$ 19$ dollars today or $\$ 25$ dollars 53 days from now?

- \$19 dollars today

○ \$25 dollars 53 days from now

Would you prefer $\$ 31$ dollars today or $\$ 85$ dollars 7 days from now?

- \$31 dollars today

- $\$ 85$ dollars 7 days from now

Would you prefer $\$ 14$ dollars today or \$25 dollars 19 days from now?

- \$14 dollars today

- \$25 dollars 19 days from now

Would you prefer $\$ 47$ dollars today or $\$ 50$ dollars 160 days from now?

○ \$47 dollars today

- \$50 dollars 160 days from now

Would you prefer $\$ 15$ dollars today or $\$ 35$ dollars 13 days from now?

○ \$15 dollars today

○ \$35 dollars 13 days from now

Would you prefer $\$ 25$ dollars today or $\$ 60$ dollars 14 days from now?

- \$25 dollars today

- \$60 dollars 14 days from now

Would you prefer $\$ 78$ dollars today or $\$ 80$ dollars 162 days from now? 
- \$78 dollars today

- $\$ 80$ dollars 162 days from now

Would you prefer $\$ 40$ dollars today or $\$ 55$ dollars 62 days from now?

○ \$40 dollars today

○ \$55 dollars 62 days from now

Would you prefer $\$ 11$ dollars today or $\$ 30$ dollars 7 days from now?

- \$11 dollars today

○ \$30 dollars 7 days from now

Would you prefer $\$ 67$ dollars today or $\$ 75$ dollars 119 days from now?

- $\$ 67$ dollars today

○ \$75 dollars 119 days from now

Would you prefer $\$ 34$ dollars today or $\$ 35$ dollars 186 days from now?

○ \$34 dollars today

- \$35 dollars 186 days from now

Would you prefer $\$ 27$ dollars today or $\$ 50$ dollars 21 days from now?

○ \$27 dollars today

○ \$50 dollars 21 days from now

Would you prefer $\$ 69$ dollars today or $\$ 85$ dollars 91 days from now?

○ \$69 dollars today

- \$85 dollars 91 days from now

Would you prefer $\$ 49$ dollars today or $\$ 60$ dollars 89 days from now?

○ \$49 dollars today

○ \$60 dollars 89 days from now

Would you prefer $\$ 80$ dollars today or $\$ 85$ dollars 157 days from now?

- $\$ 80$ dollars today

○ \$85 dollars 157 days from now

Would you prefer $\$ 24$ dollars today or $\$ 35$ dollars 29 days from now?

- \$24 dollars today

- \$35 dollars 29 days from now

Would you prefer $\$ 33$ dollars today or $\$ 80$ dollars 14 days from now?

○ \$33 dollars today

- $\$ 80$ dollars 14 days from now

Would you prefer $\$ 28$ dollars today or $\$ 30$ dollars 179 days from now?

○ \$28 dollars today

- \$30 dollars 179 days from now 
Would you prefer $\$ 34$ dollars today or $\$ 50$ dollars 30 days from now?

○ \$34 dollars today

- $\$ 50$ dollars 30 days from now

Would you prefer $\$ 25$ dollars today or $\$ 30$ dollars 80 days from now?

○ \$25 dollars today

- \$30 dollars 80 days from now

Would you prefer $\$ 41$ dollars today or $\$ 75$ dollars 20 days from now?

○ \$41 dollars today

- \$75 dollars 20 days from now

Would you prefer $\$ 54$ dollars today or $\$ 60$ dollars 111 days from now?

- \$54 dollars today

○ \$60 dollars 111 days from now

Would you prefer $\$ 54$ dollars today or $\$ 80$ dollars 30 days from now?

○ \$54 dollars today

- $\$ 80$ dollars 30 days from now

Would you prefer $\$ 22$ dollars today or $\$ 25$ dollars 136 days from now?

- \$22 dollars today

○ \$25 dollars 136 days from now

Would you prefer $\$ 20$ dollars today or $\$ 55$ dollars 7 days from now?

- \$20 dollars today

○ \$55 dollars 7 days from now 


\section{Appendix B: Additional Studies}

In addition to the studies reported in the main text, we ran a variation on Study 1 where participants were randomized into one of four conditions that manipulated both time scarcity (the adverse state) and agency, leading to a 2 (No Scarcity vs. Scarcity) x 2 (No Agency vs. Agency) between-subjects design. Unlike Study 1 in the text, No Scarcity participants did not have unlimited time to answer the cognitive aptitude questions - instead, they had 10 seconds per question to answer both the first and second set of questions. Second, these studies had an additional group, No Scarcity - Agency, which gave participants who already had 10 seconds to answer each question the ability to gain an additional four seconds per question in the second set of cognitive aptitude questions. Third, participants did not receive feedback on their performance until the end of the task - that is, there were no green checkmarks after correct answers or red X's after incorrect or blank answers. Finally, the payoff structure was slightly different: the baseline fee was lower (40 cents instead of 50 cents), as was the bonus for having more correct answers than the threshold in the second set of questions ( 25 cents instead of 50 cents). In addition, the cost of gaining more time was also lower $(50 \%$ of the baseline fee, rather than $80 \%$ ). Similar to the procedure of Study 1 in the text, individuals who chose to gain more time were routed out of the study and their time preferences data were not collected, ensuring that all Scarcity participants we observe faced the same level of scarcity.

We ran the study twice. In the first iteration (Study \#1, N=178), 20 participants chose to gain more time. Of the remaining participants, those in the Scarcity - No Agency group allocated more tokens to the earlier date-i.e., they were more impatient - than the Scarcity - Agency participants $(p=.03)$, as well as both No Scarcity group participants (both $p s<.01$ ). In the second iteration (Study \#2, $N=182$ ), seven participants chose to gain more time. Here, scarcity did not influence time preferences, and thus endowing participants with agency had a null effect as well (all $p s>.10)$.

As a robustness check of the results, we pool our results across the two waves of the aforementioned study and Study 1 in the main body of the paper and compare the choices of participants in the Scarcity - No Agency and Scarcity - Agency conditions (labeled simply as No Agency and Agency in the body of the text). Although the results are marginally significant, we find that participants in the Scarcity - No Agency group were more impatient than those in the Scarcity - Agency group, consistent with our prediction (see Supplemental Table 3). 


\section{Appendix C: Supplemental Figures}

(a)

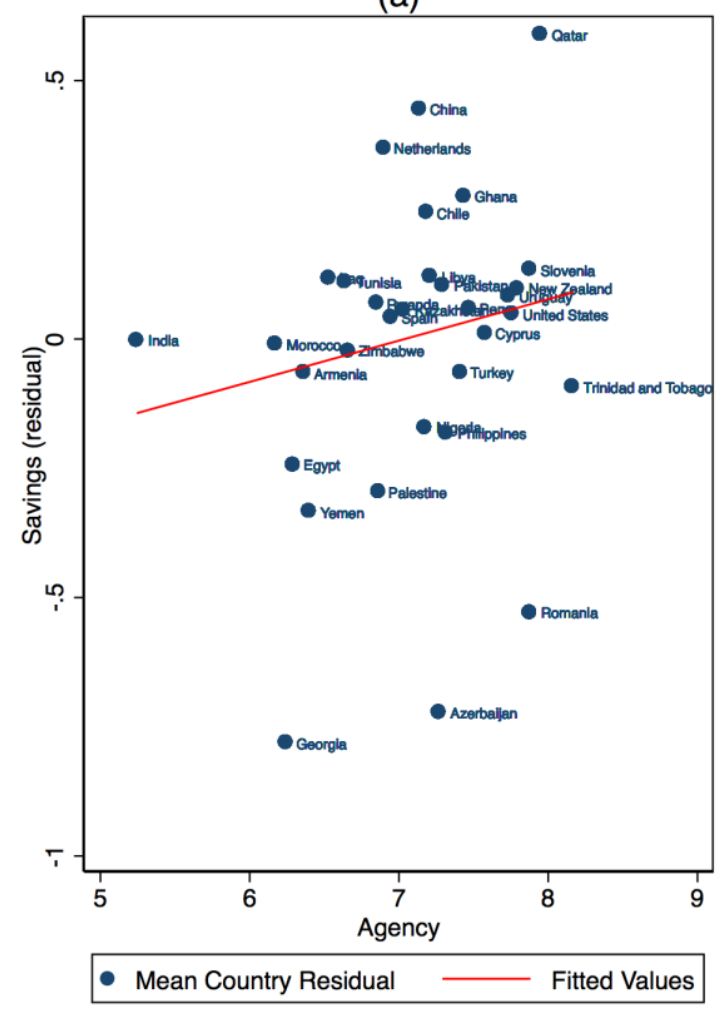

(b)

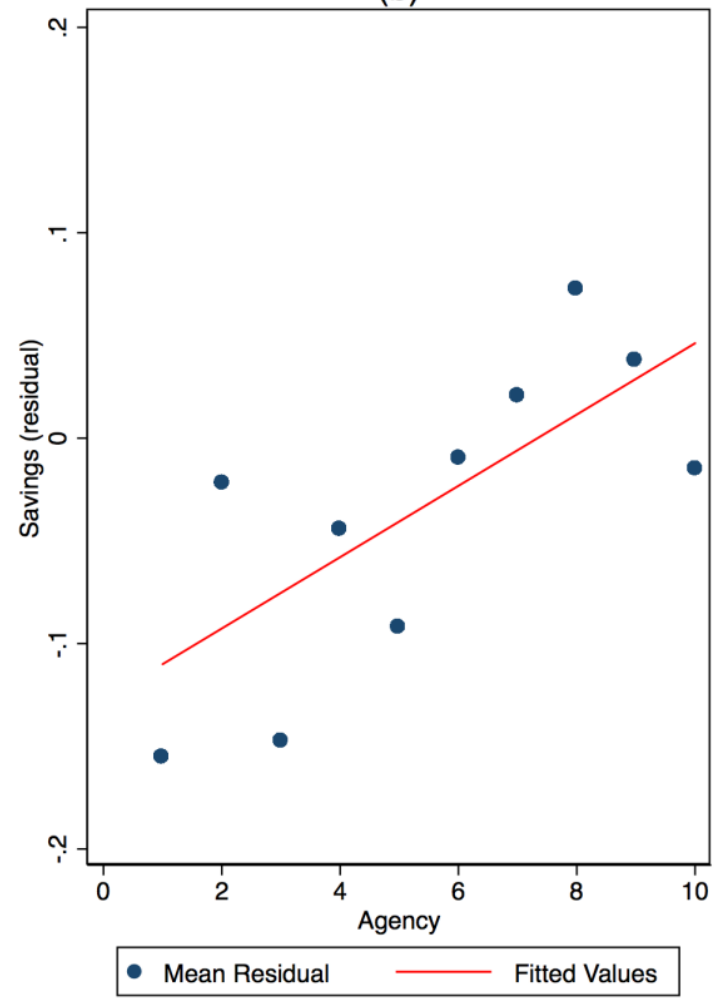

Supplemental Figure 1. World Values Survey results. N=24,683. Panel (a) shows the results of the residual analysis when dividing by country, while Panel (b) shows the results when collapsing across countries. 


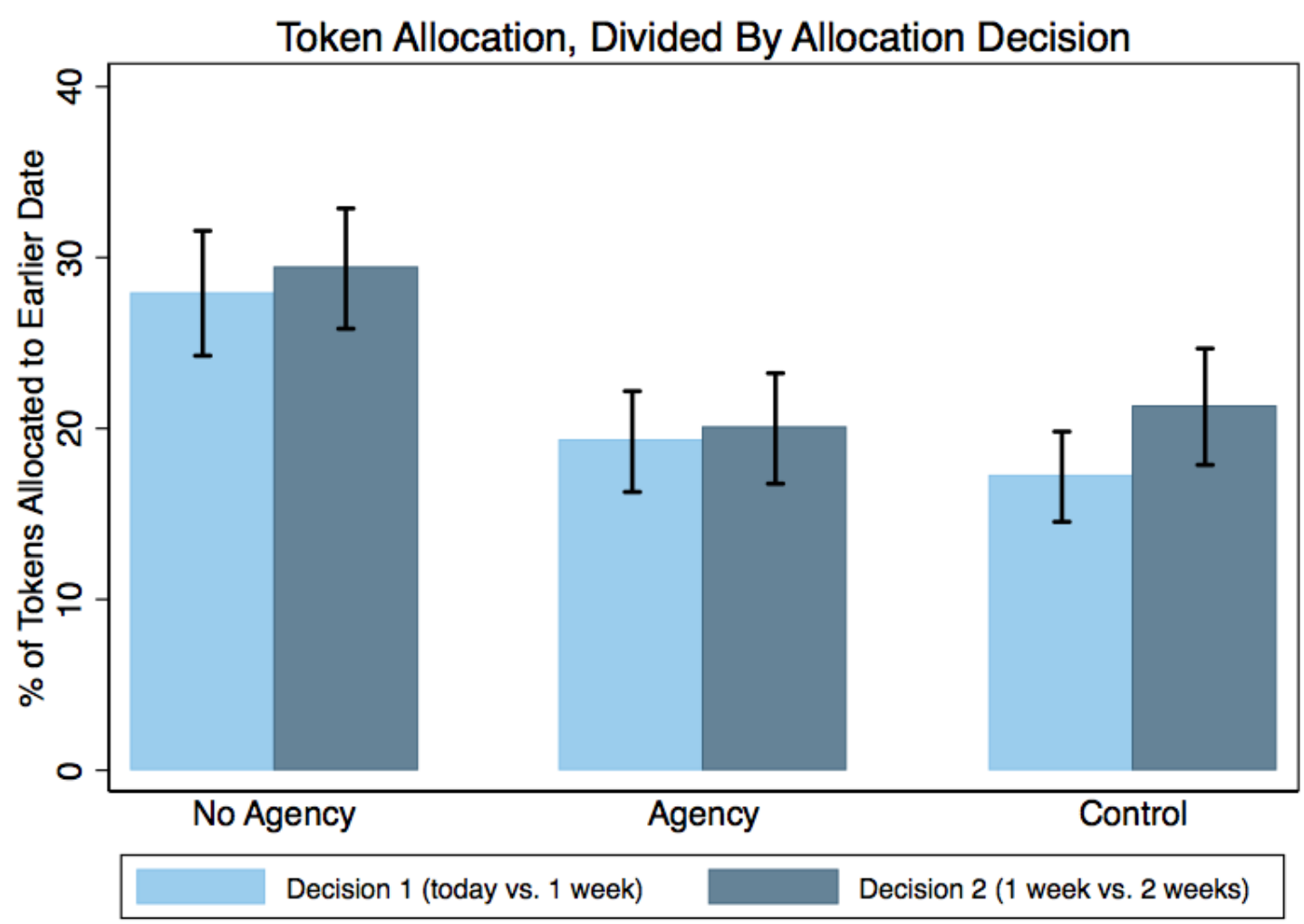

Supplemental Figure 2. Study 1 results: percent of tokens allocated to earlier dates, divided by allocation decision. $N=216$. Errors bars denote \pm 1 SE. 


\section{Appendix D: Supplemental Tables}

Supplemental Table 1. World Values Survey results.

\begin{tabular}{lcccc}
\hline & $\begin{array}{c}\text { OLS with SEs } \\
\text { Clustered at } \\
\text { Country Level }\end{array}$ & $\begin{array}{c}\text { OLS with } \\
\text { Country Fixed } \\
\text { Effects }\end{array}$ & $\begin{array}{c}\text { Logit with SEs } \\
\text { Clustered at } \\
\text { Country Level }\end{array}$ & $\begin{array}{c}\text { Ordered Logit } \\
\text { with SEs } \\
\text { Clustered at } \\
\text { Country Level }\end{array}$ \\
\hline Agency & $0.015^{* * *}$ & $0.015^{* * *}$ & $0.043^{* *}$ & $0.030 * *$ \\
Employed & $(0.004)$ & $(0.004)$ & $(0.015)$ & $(0.010)$ \\
Constant & $0.169 * * *$ & $0.169 * * *$ & $0.588^{* * *}$ & $0.379 * * *$ \\
& $(0.028)$ & $(0.028)$ & $(0.085)$ & $(0.059)$ \\
\hline $\mathrm{N}$ & $1.412 * * *$ & $2.323^{* * * *}$ & $-3.749 * * *$ & \\
$\left(\right.$ Pseudo) $\mathrm{R}^{2}$ & $(0.089)$ & $(0.097)$ & $(0.321)$ & 24381 \\
\hline
\end{tabular}

Outcome variable for (1), (2), (4): savings on scale from 1 to 4, with higher numbers indicating more savings. Outcome variable for (3): binary indicator for whether saved. Standard errors are in parentheses. All standard errors (SEs) are robust. Employed is a binary indicator for employment, equaling 1 if the respondent stated being a full time employee, part time employee, or self-employed, and 0 if s/he stated being unemployed. All other responses were coded as missing. The following control variables were omitted from the table for clarity: income decile indicators, country/year of survey interaction indicators, season of survey indicators, gender indicators, age, number of children, marital status indicators, and education indicators.

$* \mathrm{p}<0.05, * * \mathrm{p}<0.01, * * * \mathrm{p}<0.001$ 
Supplemental Table 2. Additional World Values Survey results, splitting by Organisation for Economic Cooperation and Development (OECD) and non-OECD countries.

\begin{tabular}{lcc}
\hline & OECD & Non-OECD \\
& Countries & Countries \\
\hline Agency & $0.018^{*}$ & $0.015^{* *}$ \\
& $(0.006)$ & $(0.004)$ \\
Employed & $0.217^{* * *}$ & $0.159^{* * *}$ \\
& $(0.021)$ & $(0.032)$ \\
Constant & $2.271^{* * *}$ & $1.418^{* * *}$ \\
& $(0.234)$ & $(0.085)$ \\
\hline $\mathrm{N}$ & 5100 & 19281 \\
R-squared & 0.117 & 0.214 \\
\hline
\end{tabular}

Outcome variable: savings on scale from 1 to 4 , with higher numbers indicating more savings. OLS regressions with standard errors are in parentheses. All standard errors are robust and clustered at country level. Employed is a binary indicator for employment, equaling 1 if the respondent stated being a full time employee, part time employee, or self-employed, and 0 if s/he stated being unemployed. All other responses were coded as missing. The following controls were omitted from the table for clarity: income decile indicators, country/year of survey interaction indicators, season of survey indicators, gender indicators, age, number of children, marital status indicators, and education indicators.

$\mathrm{p}<0.05, * * \mathrm{p}<0.01, * * * \mathrm{p}<0.001$ 
Supplemental Table 3. Analysis of pooled Study 1 results (see Appendix B).

\begin{tabular}{lcc}
\hline & $(1)$ & $(2)$ \\
\hline Scarcity - No Agency & $5.6^{* * *}$ & $5.0^{*}$ \\
& $(2.5)$ & $(3.0)$ \\
Study \#2 & -4.0 & $-10.7^{* * *}$ \\
Study \#3 & $(2.9)$ & $(4.1)$ \\
& $-10.1^{* * *}$ & $-12.8^{* * * *}$ \\
Second token decision & $(2.7)$ & $(3.8)$ \\
& $2.6^{* * *}$ & 1.8 \\
Constant & $(1.0)$ & $(1.2)$ \\
& $29.5^{* * *}$ & $33.6^{* * *}$ \\
R-value & $(2.2)$ & $(3.3)$ \\
\hline
\end{tabular}

Outcome variable: number of tokens allocated to earlier dates. Each participant appears in the OLS regression twice: once for each of the two convex budget token allocations. In (1), No Scarcity - No Agency, No Scarcity - Agency, and Scarcity - Agency are the omitted treatment groups, and Study \#1 is the omitted study. In (2), Scarcity-Agency is the omitted treatment group and Study \#1 is the omitted study. Studies \#1 and \#2 are those described in Appendix B, and Study \#3 is that described in the body of the paper. Standard errors in parentheses. All standard errors are robust and clustered at participant level.

$* \mathrm{p}<0.10, * * \mathrm{p}<0.05, * * * \mathrm{p}<0.01$ 